\title{
RESILIENCE QUOTIENT OF UNDERGRADUATE ACCOUNTING STUDENTS IN A PRIVATE COLLEGE
}

\author{
Brian S. Contante, BSA \\ Tayabas Western Academy, Philippines \\ *Jay Pee D. De Villa, MBA \\ Tayabas Western Academy, Philippines \\ jdevilla499@gmail.com
}

*corresponding author

\begin{abstract}
The study measured the resilience quotient of Bachelor of Science in Accountancy students of Tayabas Western Academy in Quezon, Philippines. Using the adapted standardized questionnaire of the Russell Consulting Inc. (2009), students assessed the eight dimensions namely self-assurance, personal vision, flexibility and adaptability, organized, problem solver, interpersonal competence, socially connected and proactive in a 6-scale Likert style. A complete enumeration of the 95 accounting students from all the levels during the Academic Year 2014 - 2015 was used as the sample. Findings revealed that BSA students of TWA are 'resilient' with 'personal vision' as the highest while being 'organized' as the lowest ranked dimensions. However, there was quite a high percentage of students within the lower resiliency borderline. For this, the teachers and the institution must provide more opportunities to develop students' resiliency dimensions through various academic and nonacademic programs. As the study opens door to different factors and angles on the issue, the results suggest for further scrutiny of the topic.
\end{abstract}

Keywords: resilience quotient, accounting students, undergraduate program, resilience 


\section{Introduction}

There are uncertainties that highly affect the emotional and psycho-social well-being of students. For most of the undergraduates, these uncertainties such as nature, scope and extent of a chosen course become hindrances. Enrolment to the so-called 'quota courses' offers different set of requirements and standards prompting pressured students to shift to another course, transfer school or even drop out. Although these adversities are needed for future growth and development, students face challenges, stress, odds and disruptions in their entire academic journey. On the negative side, these might weaken the psychological and emotional stability of the students if not given proper motivation and guidance. However, every human unknowingly has its own fighting mechanism to these adversities called resilience, a term that implies stability in the face of change. In education, academic resilience among students has been underscored in various studies due to its association with academic success. As defined by Hassim (2016), academic resilience refers to "an energy and drive to learn, the ability to work effectively, and achieve academically in spite of stressors and risk factors".

According to Fergus \& Zimmerman (2005), despite environmental adversities, there is increased likelihood of academic success if students are resilient. There is strong evidence that resilience can be learned and developed (Reyes, 2015) which allows students from all levels be more proactive in facing academic pressures. In the Philippines, the nature of the undergraduate programs offers variety of academic stressors during and even after the completion, a highly relevant scenario in board examination courses.

A more relevant feature is the undergraduate accounting course - Bachelor of Science in Accountancy (BSA). Students in this course are trained to pass the Certified Public Accountant (CPA) Board examination after the completion of the four or five years. Commonly tagged as one of premiere courses, colleges and universities set certain limits and standards in the academic achievement of the students to qualify and continue the course. This allows limited number of students to complete the program with the expectations of better prepared for the board examination. With the downward trend in the passing results of the CPA Board Examination, colleges and universities put more pressure on the undergraduate students. The statistics as revealed by the Professional Regulations Commission (PRC) showed from a 24.4\% passing rate on May 2013 to a $20 \%$ passed on July 
2014. As the trend is going down every examination, every institution is now tasked to bring tougher and tougher academic demands to students. With the current academic environment, Pidgeon \& Pickett (2017) add new academic stressors such as social networks, financial changes and adaptation of new family and social roles.

Several studies associate academic resilience with the academic achievement. For instance, Mwangi, Okatcha, Kinai \& Ireri (2015) found a positive and significant relationship between academic resilience and academic achievement of the 390 secondary school students in Kiambu County. This primarily explains that without resilience certain risk factors often lead to emotional dilemma, failure and dropout (Arif \& Mirza, 2017). Wills \& Hofmeyr (2018) also found that resilient students are different from lower-achieving peers in terms of socio-emotional and individual-level protective factors. There are several academic factors associated with resilience as well. Chow, Tang, Chan, Sit \& Choi (2018) found that resilience was a significant predictor of well-being while hope (Botor, 2019), self-efficacy (Cassidy, 2015), optimism (Molinero, Zayas, González \& Guil, 2018), peer connections and spirituality (Ekwonye \& DeLauer, 2019) significantly predict resilience. As resilient students interact with the environment (Zautra, 2009), the role of school, teachers and counselors are primarily important (Franklin, 2017). As Lee (2009) and Wills \& Hofmeyr (2018) suggest, caring and supportive academic community is necessary in developing academic resiliency.

This study assessed the resiliency of the BSA students of Tayabas Western Academy (TWA) despite the challenge of the course. As one of the longest-running educational institutions in Quezon, Philippines, TWA implements a screening process for students in the course through a qualifying average grade in all the accounting subjects. The evaluation and screening process is held every end of the second semester. During the academic year 2014 2015, the school conducted a comprehensive examination covering the previous year's accounting subjects. Through the process of elimination, the course can retain qualified and potential students to be CPA. However, the question arises as to how resilient the students are in facing the hurdles of the course. Through the use of the Resilient Quotient Questionnaire by Russell Consulting Inc. (2009), dimensions of human resilience were measured. This study is a prelude to an in-depth analysis of the academic resiliency of the accounting students. It serves as backgrounder for the academic administrators in the course planning and development. 


\section{Literature review}

\subsection{Factors affecting academic resilience}

According to Masten (2014), resilience is interplay between individual characteristics and the broader environment. The innate qualities of a person are generally affected by the impending forces surrounding him. As the external environment offers various forces delivering changes, chaos and challenges, a person has the ability to withstand with these forces and continue surviving. For Werner and Smith (1982), these invulnerable individuals possess remarkable set of qualities. Bernard (1991) identified traits of resilient individuals which include social competence, problem solving, autonomy and sense of purpose and belief. Brooks and Goldstein (2003) add some mind-sets common to resilient individuals such as being in control, effective communication, decision making skills, ability to establish realistic goals and expectations and capacity to learn from both success and failure. However, Masten (2001) believes that resilience is a developmental process not just a plain identification of individual qualities.

In terms of academic resilience, Pidgeon \& Pickett (2017) stress that undergraduate students face new set of stressors such as social networks, financial changes, and adaptation to new family and social roles. These external factors highly impact on the ability of the students to carry out academic demands. However, Zautra (2009) affirms that the test of resiliency begins when a person interacts with the environment. The healthy interactions with the external environment forces develop a sense of well-being. Ekwonye \& DeLauer (2019) add that social integration and peer connections are positively correlated to academic resiliency. As such, the whole school community develops the resilience of its students in which Franklin (2017) noted that school climate, the role of teacher-student and counselor relationships are important in the development of resilience in students while Lee (2009) notes on the role of caring and supportive adults.

Academic resilience is associated with several factors and indicators. For instance, Cassidy (2015) identified self-efficacy as a predictor of academic resiliency while Molinero, Zayas, González \& Guil (2018) found that optimism determines the resilience of the university undergraduate students. However, in most of the studies measuring the academic resilience of undergraduates, gender was commonly identified as important factor. For 
example, Frydenburg (2004) contended that compared to boys, girls were more disposed to, turn to others, think hopefully, and resort to tension-releasing strategies. In addition, they were more inclined to engage in these behaviors as they became older. In addition, Frydenburg and Lewis (2000) have a very good realization on the age of male and female. By the time girls reach the age of 16, they were more apt to declare personal helplessness and an inability to cope compared to boys (Frydenburg, 2004). However, turning to professionals for help with problems decreased significantly at the age of 15 than at the ages of 13 and 17 (Frydenburg, 2004). It appears imperative that youth be provided with coping strategies and other resilience based mechanisms by the age of 16 .

Another notable predictor of academic resilience is age. For example, Anasuri \& Anthony (2018) found a relationship between gender and resilience levels. For Lanuza, Rizal, Aligam \& Uy (2020), as people aged their resilience grow stronger. The same findings of Chung, Turnbull \& Chur-Hansen (2017) found that life experiences of mature-aged students contribute to higher resilience. This implies that higher level students have stronger resilience as they have developed more confidence and efficacy.

\subsection{Impact of resilience on academic performance}

According to Arif and Mirza (2017), students' psychological and emotional problems often lead to failure and dropout. In this concept comes academic resilience. For Rutter (1993) schools develop resilience of students. As most studies revealed, academic resilience and academic performance are correlated. For instance, Mwangi, Okatcha, Kinai \& Ireri (2015) found a positive and significant relationship between academic resilience and academic achievement of the 390 secondary school students in Kiambu County. It was further revealed that the moderate academic resilience of the students explained their average academic achievement. The same observation was found by Wills \& Hofmeyr (2018) on their study of 2600 Grade 6 students in South Africa. The resilient students have higher socio-emotional skills than their lower-achieving peers. It was further agreed by Masten \& Reed (2002) that academic achievement is considered appropriate indicator of resilience for school-age children. The sustenance of the academic performance is a function of the academic emotion (Alvarado, Bacalla \& Largo, 2015). It is indeed necessary that students develop higher resiliency to survive different levels of difficult situations. 
The study of Lanuza, Rizal, Aligam \& Uy (2020) showed substantial difference in the degree of academic resilience based on specialization courses. Several studies focused on the undergraduate students showed differing generalizations on the academic resilience. For example, Estimo, Arañador \& Evidente (2012) found that the students with higher resilience quotient have higher academic performance. Similarly, Deb \& Arora (2012) found that the engineering and medical students with high resilience had better academic performance. In addition, Lee (2009) observed that at-risk female students' grades are highly related to their resilience level. However, Buslig (2019) found no significant relationship between the academic resiliency and academic performance of the students in Kalinga-Apayao State College in the Philippines.

In terms of other factors and dimensions, McGillivray \& Pidgeon (2015) associate academic resilience to positive social and personal well-being. Meanwhile, Sabouripour, Hassan \& Roslan (2017) found positive relations with resilience and optimism, social support, self-efficacy and psychological well-being. Furthermore, Oluwagbemiga \& Micheal (2018) identified positive significant relationship of resilience on childhood adversity, protective family factor and community protective factor of the undergraduate students. This was supported by Salvacion, Sana \& Yanilla (2018) that there is interplay between inner strength and external support in the development of academic resilience.

\subsection{Measuring Resilience through Resilience Quotient (RQ)}

The study used the Resilience Quotient (RQ) formulated by Russell Consulting Inc. (2009) as its framework. The dimensions measured in the human resilience include the following:

Self-Assurance. It measures the high level of self-confidence to meet challenges with hope and realistic optimism.

Personal Vision. It measures what people believe in and what they want to accomplish in life.

Flexible and Adaptable. It measures the awareness of and sensitivity to the changes around them. 
Organized. It measures how people create a level of order and structure through setting shortterm goals and action planning.

Problem Solver. It measures the skills in problem analysis and creating lasting solutions.

Interpersonal Competence. It measures the ability to understand and empathize with others.

Socially Connected. It measures the quality of personal and professional network of relationships.

Proactive. It measures how people actively engage in changes around them.

The assessment has 32 statements answerable by a 6-scale Likert style interpreted as: strongly disagree (1); disagree (2); slightly disagree (3); slightly agree (4); agree (5) and strongly agree (6). There are no right or wrong answers in the assessment. The statements explore perceptions of oneself and interactions with the environment and others. Being honest in the self-assessment as to whether agree or disagree with each of the statements is critical for the most accurate RQ score. The maximum RQ score is 192. The lowest possible overall score is 32 . For individual RQ dimensions, the maximum possible score is 24 ; the lowest possible score is 4 .

\section{Figure 1}

The RQ Radar Chart

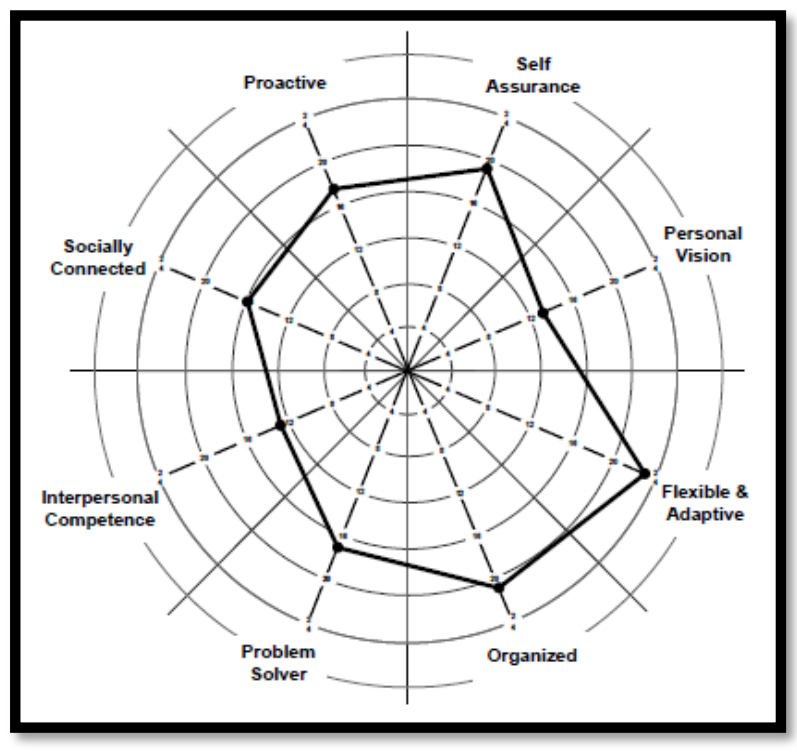

Source: Russel Consulting Inc. (http://russellconsultinginc.com/) 
In interpreting the meaning of RQ radar chart involves examining the overall size of the "wheel" (a wider suggests greater resilience) and the "balance" or proportionality of the wheel. A wheel out of balance would be evident if the scores indicated low level of resilience in one or more dimensions as compared to the other dimensions.

In order to measure the individual $\mathrm{RQ}$ dimensions, the $\mathrm{RQ}$ sheet need to be accomplished. In the RQ sheets, the 32 statements are allocated as to the dimension measured. Each score obtained per dimension is totaled to get the RQ scores. From the total of each dimension, the overall RQ score is obtained.

\section{Figure 2}

The RQ Score Sheet

\begin{tabular}{|c|c|c|c|c|c|}
\hline RQ Dimensions & \multicolumn{4}{|c|}{ Tally Box } & $\overline{\text { RQ Scores }}$ \\
\hline Self-Assurance & 1: & 9: & 17: & 25: & \\
\hline Personal Vision & 2: & $10:$ & 18: & 26: & \\
\hline Flexible and Adaptable & 3: & 11: & 19: & 27: & \\
\hline Organized & 4: & 12: & 20: & 28: & \\
\hline Problem Solver & 5: & 13: & 21: & 29: & \\
\hline Interpersonal Competence & 6: & 14: & 22: & $30:$ & \\
\hline Socially Connected & 7: & 15: & 23: & 31: & \\
\hline Proactive & 8: & 16: & 24: & 32: & \\
\hline
\end{tabular}

Source: Russel Consulting Inc. (http://russellconsultinginc.com/)

The overall RQ scores are explained as follows:

171 to 192 Very Resilient: An individual is consistently able to deal effectively with and even thrive on change. He has effective mechanisms in place that give direction, structure, support and self-confidence.

153 to 170 Resilient: Most of the time the individual is able to deal with change in a positive manner. He has a number of mechanisms in place that help deal with the uncertainty of change. 
132 to 152 Somewhat Resilient: Change occasionally knocks off an individual's best performance. He has some difficulty regaining footing. While he has a number of stabilizing mechanisms in place, he could work at developing and exercising more of them.

32 to 131 Lower Resilience: Change creates major challenges for an individual. He is frequently unprepared for the uncertainty and lack of stability that change creates. While there are times when he is able to find stability and focus, he needs to develop and enrich a broad range of resilience capacities.

\section{Methodology}

This study employed the descriptive-quantitative research method. It surveyed the students enrolled in the Bachelor of Science in Accountancy at the Tayabas Western Academy, a private college in Quezon, Philippines during the first semester of the academic year 20142015. There was complete enumeration of the 95 enrolled students from the first level to the fourth level. The demographic profile of the students is presented in the following tables.

\section{Table 1}

Demographic Profile of BSA students in terms of Gender

\begin{tabular}{ccc}
\hline Gender & Frequency & Percentage \\
\hline Male & 28 & $29.47 \%$ \\
Female & 67 & $70.53 \%$ \\
\hline Total & 95 & $100.00 \%$ \\
\hline
\end{tabular}

\section{Table 2}

Demographic Profile of BSA students in terms of Age

\begin{tabular}{lcc}
\hline \multicolumn{1}{c}{ Age } & Frequency & Percentage \\
\hline 16 years old and below & 23 & $24.21 \%$ \\
17 to 20 years old & 51 & $53.68 \%$ \\
21 to 24 years old & 18 & $18.95 \%$ \\
25 years old and above & 3 & $3.16 \%$ \\
\hline Total & 95 & $100.00 \%$ \\
\hline
\end{tabular}


The researcher adapted the standard questionnaire of Russel Consulting Inc. (2009) on the resiliency profile of the respondents that contains the questions relevant to the eight human dimensions of resilience: self-assurance; personal vision; flexible and adaptable; organized; problem solver; interpersonal competence; socially connected; and proactive.

The researcher personally conducted the data gathering through a secured permission from the college authorities to conduct the survey. During the classroom visit to conduct the survey, the researcher introduced and explained the purpose of the study prior to the distribution of the questionnaire. Questionnaires were then retrieved, checked and verified after the completion. The data gathered were tabulated and calculated using the standard score sheet. The scores of each dimension were calculated using frequency, percentage and mean.

\section{Findings and Discussion}

Table 3 summarizes the eight dimensions of the resilience quotient of the undergraduate accounting students in Tayabas Western Academy. The results of the assessment were measured in terms of frequency and percentage. The eight dimensions were assessed using several statements reflecting their attitudes and characteristics.

In terms of self-assurance, $4.21 \%$ got the highest score of 24 , the highest individual score for each resilience dimensions. Most of the respondents scored 19 and 20 in this dimension whereas more than $50 \%$ of the respondents scored from 18 to 21 . The statements included under the dimension include: "I believe that I have the knowledge, skills, and abilities to deal with almost anything that happens to me" (statement 1), "I think and speak positively about myself and my abilities when facing a challenge or stress" (statement 9), "When I face difficult challenges I am able to maintain confidence in my ability - one way or another - to overcome the challenge" (statement 17), and "When I face great challenges, I look within myself for the answers about what to do and how to respond to the challenge" (statement 25). Majority of the students assessed were not fully developed in this dimension. Although they scored far beyond the average, it can be inferred that they need more 
INTERNATIONAL JOURNAL OF ACCOUNTING, FINANCE AND EDUCATION

Volume 1, Issue 1 - September 2020 • ISSN 2719-0595 (PRINT) 2719-0609 (ONLINE)

motivation to develop high self-assurance and face their own challenges with confidence so as not to lose self-esteem.

Table 3

The Eight (8) Dimensions of Resilience Quotient

\begin{tabular}{ccccccccc}
\hline Scores & Self -Assurance & \multicolumn{2}{l}{ Personal Vision } & \multicolumn{2}{c}{$\begin{array}{c}\text { Flexibility and } \\
\text { Adaptability }\end{array}$} & Organized \\
& & & & & & & & \\
\hline & F & \% & F & \% & F & \% & F & \% \\
\hline 13 & & & & & & & 1 & 1.05 \\
14 & & & & & 1 & 1.05 & 1 & 1.05 \\
15 & 1 & 1.05 & 1 & 1.05 & 3 & 3.16 & 3 & 3.16 \\
16 & 2 & 2.11 & 4 & 4.21 & 3 & 3.16 & 7 & 7.37 \\
17 & 8 & 8.42 & 3 & 3.16 & 8 & 8.42 & 10 & 10.53 \\
18 & 12 & 12.63 & 12 & 12.63 & 13 & 13.68 & 17 & 17.89 \\
19 & 17 & 17.89 & 11 & 11.58 & 17 & 17.89 & 16 & 16.84 \\
20 & 18 & 18.95 & 14 & 14.74 & 17 & 17.89 & 16 & 16.84 \\
21 & 15 & 15.79 & 11 & 11.58 & 13 & 13.68 & 9 & 9.47 \\
22 & 9 & 9.47 & 25 & 26.32 & 14 & 14.74 & 8 & 8.42 \\
23 & 9 & 9.47 & 10 & 10.53 & 5 & 5.26 & 4 & 4.21 \\
24 & 4 & 4.21 & 4 & 4.21 & 1 & 1.05 & 3 & 3.16 \\
\hline
\end{tabular}

\begin{tabular}{|c|c|c|c|c|c|c|c|c|}
\hline \multirow[t]{2}{*}{ Scores } & \multicolumn{2}{|c|}{ Problem Solver } & \multicolumn{2}{|c|}{$\begin{array}{c}\text { Interpersonal } \\
\text { Competence }\end{array}$} & \multicolumn{2}{|c|}{$\begin{array}{c}\text { Socially } \\
\text { connected }\end{array}$} & \multicolumn{2}{|c|}{$\begin{array}{l}\text { Proactive } \\
\text { dimension }\end{array}$} \\
\hline & $\mathbf{F}$ & $\%$ & $\mathbf{F}$ & $\%$ & $\mathbf{F}$ & $\%$ & $\mathbf{F}$ & $\%$ \\
\hline 11 & 1 & 1.05 & & & & & & \\
\hline 13 & & & & & 1 & 1.05 & & \\
\hline 14 & 3 & 3.16 & & & & & & \\
\hline 15 & 2 & 2.11 & 4 & 4.21 & 1 & 1.05 & 2 & 2.11 \\
\hline 16 & 7 & 7.37 & 4 & 4.21 & 5 & 5.26 & 2 & 2.11 \\
\hline 17 & 10 & 10.53 & 12 & 12.63 & 8 & 8.42 & 13 & 13.68 \\
\hline 18 & 13 & 13.68 & 15 & 15.79 & 11 & 11.58 & 8 & 8.42 \\
\hline 19 & 17 & 17.89 & 12 & 12.63 & 21 & 22.11 & 20 & 21.05 \\
\hline 20 & 17 & 17.89 & 18 & 18.95 & 14 & 14.74 & 15 & 15.79 \\
\hline 21 & 7 & 7.37 & 13 & 13.68 & 14 & 14.74 & 16 & 16.84 \\
\hline 22 & 10 & 10.53 & 12 & 12.63 & 12 & 12.63 & 9 & 9.47 \\
\hline 23 & 6 & 6.32 & 3 & 3.16 & 5 & 5.26 & 5 & 5.26 \\
\hline 24 & 2 & 2.11 & 2 & 2.11 & 3 & 3.16 & 5 & 5.26 \\
\hline
\end{tabular}


In terms of personal vision, $4.21 \%$ got the perfect score $24,1.05 \%$ got the lowest score 15. Most of the respondents scored 22 while $87.38 \%$ scored between 18 and 23. Under this dimension, the statements assessed were: "I know what's important to me in my life" (statement 2); "When I look back on my life, I see a clear pattern in the choices and decisions that I have made" (Statement 10), "I have a pretty good idea of what I want to accomplish in my work and life" (Statement 18), and "I know what I need to do to achieve my personal and professional goals" (Statement 26). The results under this dimension assert that students have pre-set goals prior to enrolment in the course. It is a well-known fact that students are trained to begin with the end in mind. Enrolment in the course needs mental conditioning that they need to pass the CPA board examination after graduation.

The results of the flexible and adaptable dimension show a range of 15 to 24 . The scores 19 and 20 are the most frequently obtained wherein $17.89 \%$ of the respondents scored at this level. The lowest score obtained in this dimension is 14. Included in this dimension are "I approach new situations with an open mind as to what needs to be done" (statement 3), "I am willing and able to make adjustments to my goals and plans when situations and expectations of me change" (statement 11), "I find that, most of the time, I am able to find a way to meet both my needs and the needs of others in a changing environment or during conflict" (statement 19), and "I can usually accommodate others' needs (adjust my behaviors) while remaining true to my personal goals" (statement 27). Results imply that most of the students are flexible enough to the changing situations in the environment. However, the flexibility and adaptability should be treated with much complexity because these might be affected by several factors such as work overload, time management and personality changes.

The scores of the respondents in terms of being organized range from the highest possible score of 24 to the lowest score of 13. The highest frequency in this dimension was the score of 18 with an equivalent percentage of 17.89 . Being organized is reflected by the following: "When faced with a major change, I usually find a way to create systems or structures that give me a degree of control that I find useful and helpful" (statement 4); "I start each work day by thinking about what I need to accomplish during that day and I end each day reviewing what I need to accomplish the next day" (statement 12); "I usually 
maintain some sort of a "to-do" list to help me focus on what I need to work on" (statement 20); and "When I am confused about what I need to do or the choices I need to make, I usually try to write out my thoughts" (statement 28). Putting things right and prioritizing things that matter help them grow as students and professionals. However, the results show that students need more development in this criterion. There were students who scored lower than the rest of the students in the course as reflected by the scores of 13,14 and 15 with 1,1 and 3 respondents, respectively. This dimension is enhanced by the institution in various activities and programs handled by the students such as leadership trainings, seminars, team buildings and the likes.

As a problem solver, $2.11 \%$ of the students scored the highest possible of 24 . The lowest score was 11 while 19 and 20 were the most frequent scores in this dimension. A total of $62.10 \%$ respondents scored 17 to 20 . This dimension includes "When I have a problem to solve or a decision to make, I usually spend time defining the problem or decision" (statement 5), "I see the problems that I face in life and at work as challenges that I can solve" (statement 13), "I usually try to get down to the root cause of a problem before I try to solve it" (statement 21), and 'When I solve problems or make decisions I try to identify the relationships between the problem I am solving or decision I am making with other issues, problems, and challenges" (statement 29). It is clear that most of the students were not inclined to being a problem solver. The generation today faced several destructions and the changing demographics suggest that there are different ways to face problems. Most of the students have different outlets, tend to cool down the problem and try the 'quick fix' not solve the roots of the problem.

In terms of interpersonal competence, $4.21 \%$ got the lowest score of 15 while only two got the perfect score of 24. The most frequent score was 20 where $18.95 \%$ of the respondents scored at this level. The traffic of the respondent falls to the scores 17 to 22 . Statements included in this dimension are: "In social interactions at work and in my personal life" (statement 6), "I am usually able to laugh at myself when appropriate, "I find it easy to empathize with others' frustrations, hurts, joys, misfortunes, and successes” (statement 14), "In stressful or conflict situations I am usually able to maintain effective relationships with others" (statement 22), and "I value the diverse beliefs, approaches, and methods that people 
bring to their work and their daily interactions with me" (statement 30). This dimension is one of the most important in a professional life. As soon as the students graduate, they have to face the reality that networking, making friends and alliances with various people develop a strong personality. The results show that students have a healthy relationship with other people. This is basically enhanced by different departmental activities being held for socialization, learning and fun.

The highest score in terms of socially connected dimension was 24 while the lowest was 15 . The traffic of respondents fell within the range 18 to 22 . The most frequent score was 19 , equivalent to $22.11 \%$. This dimension includes: "I have a diverse group of people whom I consider good friends" (statement 7), "I find it easy to form lasting friendships" (statement 15), "I frequently turn to my circle of friends when I am frustrated, confused, angry, or uncertain - and when I have great news to share" (statement 23), and "I regularly participate in one or more non-work-related group activities with friends (e.g., church, sports, cultural, etc.) where I can let off steam, learn, grow, and have fun" (statement 31). The emergence of various outlets that students share, interact and make friends whether virtual or real added much to this dimension. At this era of globalization, students tend to be more dynamic in networking and staying connected with people from all walks of life.

In terms of being proactive, the most frequent score was 19 which $21.05 \%$ of the students obtained. Being proactive is reflected by "I view change - even difficult and challenging change — as an opportunity for me to learn and grow" (statement 8), "When an unwelcome change is forced upon me, I can usually find a way to either influence the course of the change or find a way to make the change work for me on my terms" (statement 16), "Rather than focusing on what others are doing to me" (statement 24), "I tend to focus my energy on how I can make the best of a situation", and "I believe that my own decisions and actions during a change will make the biggest difference in how the change affects me" (statement 32). Being proactive means looking at the future horizon. As the scores of the students tend to be high enough in this dimension, it was clear that students look at the present as a challenge to develop their future. 
INTERNATIONAL JOURNAL OF ACCOUNTING, FINANCE AND EDUCATION

Volume 1, Issue 1 · September 2020 • ISSN 2719-0595 (PRINT) 2719-0609 (ONLINE)

\section{Table 4}

Overall Resilience Quotient Score Range

\begin{tabular}{ccc}
\hline Scores & Frequency & Percentage \\
\hline $32-131$ & 2 & $2.11 \%$ \\
$132-152$ & 35 & $36.84 \%$ \\
$153-170$ & 41 & $43.16 \%$ \\
$171-192$ & 17 & $17.89 \%$ \\
\hline
\end{tabular}

Table 4 uses the ranges and interpretations as stated in the RQ framework in the analysis of the overall resilience quotient of the accounting students. Based from tabulated overall scores, $17.89 \%$ of the students are very resilient, $43.16 \%$ are resilient, $36.84 \%$ are somewhat resilient and $2.11 \%$ are lower resilience. The results are quite alarming that most of the students scored below the threshold of being and not being resilient. These areas need to be developed further to make students very resilient and face challenges with great vigor and courage. The small percentage of the students who scored very resilient is an indication that the school needs an intervention program for them to stay in the course and pursue their dreams of becoming the next CPA.

\section{Table 5}

Overall Weighted Mean of Resiliency Profile and Overall RQ Score

\begin{tabular}{|c|c|c|}
\hline Resiliency Profile & Mean & Rank \\
\hline Self-Assurance & 19.98 & 2 \\
\hline Personal Vision & 20.44 & 1 \\
\hline Flexibility and Adaptability & 19.58 & 5 \\
\hline Organized & 19.08 & 8 \\
\hline Problem Solver & 19.11 & 7 \\
\hline Interpersonal Competence & 19.37 & 6 \\
\hline Socially Connected & 19.64 & 4 \\
\hline Proactive & 19.75 & 3 \\
\hline Overall RQ Score & 156.95 & \\
\hline
\end{tabular}


Table 5 shows the highest mean score of 20.44 on personal vision while the lowest score of 19.08 on the 'organized' dimension. The ranking of other dimensions in descending order is self-assurance (19.98), proactive (19.75), socially connected (19.64), flexibility and adaptability (19.58), interpersonal competence (19.37), and problem solver (19.11). Based on the interpretation from the RQ framework, the overall RQ score of the accounting students is interpreted as 'resilient'. The overall tabulation suggests that students need more development programs to be very resilient. As there are always rooms for improvement, the results should serve as wake up call for responsible persons to make necessary programs for further growth of the students.

\section{Conclusion}

The study measured the resilience quotient of the 95 BSA students of Tayabas Western Academy using the standard questionnaire adapted from the Russell Consulting Inc. There were eight dimensions namely self-assurance, personal vision, flexibility and adaptability, organized, problem solver, interpersonal competence, socially connected and proactive which were assessed using a 6-scale Likert style questionnaire. Findings show that BSA students of TWA are resilient where they can deal with change in a positive manner and they have mechanisms in dealing with uncertainties of change. Based on the scores, $43.16 \%$ are resilient, $36.84 \%$ are somewhat resilient, $17.89 \%$ are very resilient and $2.11 \%$ have lower resilience. In terms of the individual dimensions, the highest scored dimension is personal vision (20.44) while the lowest is organized (19.08). The overall resiliency quotient was 156.95 , interpreted as resilient.

Although the overall assessment found that students are resilient, there were high percentage of students within the borderline of resiliency as depicted by $36.84 \%$ somewhat resilient and $2.11 \%$ lower resilience. For this, the teachers and the institution must provide more opportunities to develop students' resiliency dimensions through various academic and non-academic programs. Key focus on the team work and group strategy to support weak students with peer learning and mentoring. Relevant to the findings of cited studies that academic resilience is correlated to academic achievement, the teachers should motivate 
students to strive hard so they can pursue and become CPAs. Nonetheless, the results suggest for further department developmental plans.

As the study opens door to different factors and angles on the issue, the results suggest for further scrutiny of the topic. The authors admit various limitations of the study including statistics and scope. Since the study is a prelude to a more comprehensive scope, it has lay down the foundation for determining the level of students' resilience. It is suggested to develop further analysis on the topic including gender analysis, correlation to academic achievement and relation to the passing of the board examination.

\section{References}

Alvarado, E.T., Bacalla, L.A. \& Largo, R.C. (2015). Predictive Academic Regulation and Emotion on Academic Resiliency Among Selected CNU Scholars. Proceedings of 7th IASTEM International Conference, Manila, Philippines, 13th December 2015.

Anasuri, S. \& Anthony, K. (2018). Resilience Levels Among College Students: A Comparative Study from Two Southern States in the USA. IOSR Journal Of Humanities And Social Science (IOSR-JHSS) Volume 23, Issue 1, Ver. 3, pp 52-73

Arif, Muhammad Irfan \& Mirza, Munawar S. (2017). Effectiveness of an Intervention Program in Fostering Academic Resilience of Students at Risk of Failure at Secondary School Level. Bulletin of Education and Research, Vol. 39, No. 1 pp. 251264

Bernard, B. (1991). Fostering Resiliency In Kids: Protective Factors In The Family, School, And Community. Western Regional Center for Drug-Free Schools and Communities. August, 1-32.

Botor, N.J. (2019). Hope Predicts Happiness with Life, Personal Well-Being, and Resilience Among Selected School-going Filipino Adolescents. International Journal of Sciences: Basic and Applied Research (IJSBAR) (2019) Volume 47, No 2, pp 125-141

Brooks, R. \& Goldstein, S. (2003). The Power of Resilience: Achieving Balance, Confidence, and Personal Strength in Your Life, Kindle Edition. New York: McGraw Hill. 
Buslig, S.A. (2019). The Academic Resilience of College Students in Kalinga. International Journal of Humanities and Social Science, Vol. 9, No. 6, DOI: doi:10.30845/ijhss.v9n6p7

Cassidy, S. (2015). Resilience Building in Students: The Role of Academic Self-Efficacy. Frontiers in Psychology. Volume 6, pp $1-14$

Chow, K.M., Tang, W.K., Chan, W.C., Sit, W.J. \& Choi, K.C. (2018). Resilience And WellBeing Of University Nursing Students In Hong Kong: A Cross-Sectional study. BMC Medical Education (2018) 18:13, pp 2 - 8. DOI: 10.1186/s12909-018-1119-0

Chung, E., Turnbull, D. \& Chur-Hansen, A. (2017). Differences In Resilience Between 'Traditional' And 'Non-Traditional' University Students. Active Learning in Higher Education 18(1): 77-87. DOI: 10.1177/1469787417693493

Deb, A., \& Arora, M. (2012). Resilience And Academic Achievement Among Adolescents. Journal of the Indian Academy of Applied Psychology, 38(1), 93-101.

Ekwonye, A.U. \& DeLauer, V. (2019). Exploring Individual and Interpersonal Level Factors Associated with Academic Success of College Students at a Women's, Faith-based Higher Institution. Higher Education Studies, Vol. 9, No. 1; 2019, pp 86 - 99

Estimo, E., Arañador, L. \& Evidente, L.G. (2012). Collaborative Learning in Small Group Discussions and Its Impact on Resilience Quotient and Academic Performance. JPAIR Multidisciplinary Research 7(1). DOI: 10.7719/jpair.v7i1.159

Franklin, S. (2017). Exploring Organizational Factors That Influence Resilience And Persistence Among High School Students Of Color. Theses, Projects, and Dissertations. 596. https://scholarworks.lib.csusb.edu/etd/596

Frydenberg, E. (2004). Teaching Young People To Cope. In: Frydenberg E, editor. Thriving, Surviving or Going Under: Coping with Everyday Lives. Greenwich: Information Age Publishing; 2004. pp. 189-206.

Frydenberg, E. \& Lewis, R. (2000). Adolescent Least Able To Cope: How Do They Respond To Their Stresses? British Journal of Guidance and Counselling. 2004; 32(1): 25-36. http://dx.doi.org/10.1080/03069880310001648094.

Hassim, T. (2016). Academic Resilience: A Systematic Review Of Protective Factors For Undergraduate Students In Higher Education. Dissertation submitted in fulfillment of 
the requirements for the degree Master of Arts in Positive Psychology at the Potchefstroom Campus of the North-West University

Lanuza, M.H., Rizal, R.G., Aligam, N.P. \& Uy, R. (2020). Contextualize Program Of Strengthening Academic Resilience Level Of The Secondary Education Students. Journal of critical reviews. Vol. 7, Issue 11, 2020

Lee, D.D. (2009). Impact of Resilience on academic Achievement of At-Risk Students in Upward Bound Program in Georgia. Electronic Theses and Dissertations. 202. https://digitalcommons.georgiasouthern.edu/etd/202

Masten, A.S. \& Reed, M.J. (2002). Resilience In Development. In: Snyder CR, Lopez SJ, editors. Handbook Of Positive Psychology. Oxford University Press; New York: 2002. pp. 74-88.

Masten, A. (2014). Resilience In Individual Development: Successful Adaptation Despite Risk And Adversity. In M.C. Wang \& E.W. Gordon (Eds.), Educational resilience in inner-city America: Challenges and prospects (pp. 3-25). Hillsdale, NY: Lawrence Erlbaum.

Masten A. (2001). Ordinary Magic: Resilience Processes In Development. American Pyschologist, 56, 227-238.

McGillivray, C.J. \& Pidgeon, A.M. (2015). Resilience Attributes Among University Students: A Comparative Study of Psychological Distress, Sleep Disturbances And Mindfulness. European Scientific Journal February 2015 edition vol.11, No.5, pp 33 48

Molinero, R.G., Zayas, A., González, P.R. \& Guil, R. (2018). Optimism And Resilience Among University Students. International Journal of Developmental and Educational Psychology Revista INFAD de psicología 1(1):147. DOI: 10.17060/ijodaep.2018.n1.v1.1179

Mwangi, C.N., Okatcha, F.M., Kinai, T.K. \& Ireri, A.M. (2015). Relationship between Academic Resilience and Academic Achievement among Secondary School Students in Kiambu County, Kenya. International Journal of School and Cognitive Psychology. S2: 003. doi: 10.4172/2469-9837.S2-003, pp 2 - 5 
Oluwagbemiga, O. \& Micheal, J. (2018). Childhood Adversity and Factors Determining Resilience among Undergraduate Students. International Journal of Emergency Mental Health and Human Resilience, Vol.20, No. 2, pp 1-9

Pidgeon, A. M., \& Pickett, L. (2017). Examining the Differences Between University Students' Levels of Resilience on Mindfulness, Psychological Distress and Coping Strategies. European Scientific Journal, ESJ, 13(12).

Reyes, A.T. (2015). Nursing Students' Understanding and Enactment of Resilience: A Grounded Theory Study. Electronic Thesis and Dissertation Repository. 2836. https://ir.lib.uwo.ca/etd/2836

Russell Consulting Inc. (2009). Your resilience quotient. Retrieved from http://bulletproofpeople.com.au/wp-content/uploads/2013/09/Measuring-your Resilience1.pdf, July 15, 2014

Rutter, M. (1993). Resilience: Some Conceptual Considerations. Journal of Adolescent Health, 14, 626-631.

Sabouripour, F., Hassan, N.C. \& Roslan, S. (2017). Predictors of Resilience among Iranian Graduate Students in University Putra Malaysia. International Journal of Academic Research in Business and Social Sciences Vol. 7, Special Issue, pp 996 - 1011. DOI: 10.6007/IJARBSS/v7-i14/3756.

Salvacion, M.S., Sana, E.A. \& Yanilla, N.F. (2018). Academic Resilience among Selected Students of the School of Health Sciences- Baler, Philippines. Phil J Health Res Dev, Vol.22 No.4, 27-35

Werner, E.E., and Smith, R.S. (1982). Vulnerable, But Invincible: A Longitudinal Study Of Resilient Children And Youth. New York: McGraw-Hill.

Wills, G. \& Hofmeyr, H. (2018). Academic Resilience in Challenging Contexts: Evidence From Township and Rural Primary Schools in South Africa. Stellenbosch Economic Working Papers: WP18/2018 www.ekon.sun.ac.za/wpapers/2018/wp182018

Zautra, A.J. (2009). Resilience: One Part Recovery, Two Parts Sustainability. J. Pers. 77, 1935-1943. DOI:10.1111/j.1467-6494.2009.00605.x

Fergus S, Zimmerman M. (2005). Adolescent Resilience: A Framework For Understanding Health Development In The Face Of Risk. Annu. Rev. Public Health, 26:399-419. 